\title{
Quality of Life and Hopelessness among Adolescent Rag Pickers of Delhi, India
}

\author{
Akbar Hussian*, Monu Lal Sharma \\ Department of Psychology, Jamia Millia Islamia University, India
}

Copyright (C) 2016 by authors, all rights reserved. Authors agree that this article remains permanently open access under the terms of the Creative Commons Attribution License 4.0 International License

\begin{abstract}
Rag pickers are marginalized section of our society. India grappling the problem of shelter particularly in the urban societies besides other socio economic problems likes other Asian countries. Children living and working on streets are bound to adopt substandard life style due to lack of basic facilities. As results their quality of life includes physical health, social and psychological functioning severely destabilized and tends to develop sense of insecurity, hopelessness, depression, anxiety etc. Therefore, the study was conducted on the adolescents engaged in rag picking on the streets of Delhi to measure their quality of life and its impact on future perspective thinking. For that purpose sixty rag pickers were taken incidentally from different localities of Delhi. The participants of were male and between the age range of $12-18$ engaged in rag picking. Sixty adolescents not engaged in rag picking and living with the parents were also taken from the same locality. WHOQOL-BREF and Beck hopelessness scales (BHS) were administered on both the groups of participants to assess their quality of life and sense of hopelessness. The finding suggested that rag picker adolescents were found suffering from significantly poor quality of life as well as higher degree of hopelessness. Findings further indicated negative relationship between quality of life and sense of hopelessness.
\end{abstract}

Keywords Homelessness, Hopelessness, Quality of Life, Rag Pickers

\section{Introduction}

Millions of children live on the streets of cities across the globe. Homelessness is a very common problem in developing nations like India. Poverty, urbanization, rapid economic growth, the breakdown of families, and domestic violence are considered to be some of the most immediate causes of the problem. The actual figure of children living on streets is difficult to assess because it is continuously rising. In every city street children engaged in rag picking in and around densely populated areas can be found very easily.
The living conditions and quality of life of such population appear to be miserable as they usually tolerate constant hunger and suffers from malnourishment, which make them vulnerable to health related problems. For the sake of survival, adolescents working on street and perform variety of jobs including the collection of plastic, aluminium, paper, and anything else that can be resold. Sometime they are also found to be engaged in begging. Their poor quality of life expose them too many health related risk and derive them to be involved in illegal activities like drug trafficking, organ trades, prostitution and slavery especially in metropolitan cities. Such type of situations makes their life complex which in turn develops many psychological problems such as anxiety, psychological trauma, alienation, and feeling of hopelessness as a result they become psychologically vulnerable as well. Psychologically, these children are deprived of love, affection and family's sympathy.

As far as quality of life is concerned it is defined in many ways and its measurement and incorporation into scientific study is not steady or easy. The World Health Organization defines Quality of Life as 'The individual's perception of his or her position in life, within the cultural context and value system he/she lives in, and in relation to his or her goals, expectations parameters and social relations. Every culture has different factors affecting quality of life and measures psychological, physical, social as well as economic well-being of the individuals. The general concept of quality of life was basically overlapping with the traditional concepts of health and functional status. An ideal health assessment, therefore, would include a measure of the person's physical health, a measure of physical, social and psychological functioning, and a measure of quality of life.

Poverty is one of the most serious social concerns across the world today. Among the poor, the most vulnerable section of the society is people living on the streets. Whether they are gangs of street youth or panhandling drifters, no society is unaffected by the social problem of homelessness. The existing literature on street children or adolescents strongly suggests that there are many problems associated with life without a home. Studies have shown that homelessness is also associated with behaviour problem in 
children (Edleman and Mihaly, 1989; Di Biase and Waddell, 1995), higher exposure to trauma, increased anger and depression (Marshall Burnam, Koegel, Sulliuan, Bengnun, 1996).

Arguably, one of the most important problems of children living on the streets or part of slum is feeling of hopelessness about the future. McLaughlin, Miller, and Warwick (1996) propose that an individual's sense of hopelessness can be defined in terms of a system of negative expectations concerning self and future life. When hopelessness arises, the person begins to distort reality by pessimistic thinking. $\mathrm{He}$ or she may be convinced that the negative situation will not improve and will probably get worse. Metalsky and Joiner (1992) have indicated that hopelessness involves the following cognitions: attributing bad events to unavoidable and far-reaching causes, drawing negative conclusions about the self from a negative event, and assuming one event will lead to others in the future.

With the adverse circumstance and quality of life it's difficult to cope with daily events and develop mechanism. They need to be self- resilient or build capacity to cope with daily stressors and adversity. Due to lack of proper bathing facilities and opportunities many non-beneficiary street children had to stay without bathing for 2-3 days together. Such denial of bathing is an example of short term avoidance coping mechanism (Hai, 2014). With the rag-pickers resilient factors may be social support, optimism, involvement in religious activity, education programme, etc. Ragpicking profession is not a begging and they works hard to earn livelihood. It supports them economically and provides ample amount of free time. They feels proud to be a rag-picker and considers themselves master of their own life. Their communication and process of socialization were very limited and as they socialized among themselves as they share food, shelter, money, problems and love with their age group children to cope with the daily life events. The Hindu Daily (2008) reported that the Former President of India Dr. A.P.J Abdul Kalam said "Child Rag-pickers are not Street Children" while addressing a programme PVR street to school: Child Rag-pickers are the children of hope, they are children of hope. We do not brand them as street children we have to give them confidence.

There is little agreement about the possible relationship between social phenomenon of quality of life and psychological factors like feeling of hopelessness. Although past researches have focused on psychopathology, incidence of trauma, and the demography of the homeless, little attention has been paid in the psychological literature to the overall quality of life of the children or adolescents living on streets. Instead, the bulk of the research literature has been confined to clinical aspects of homelessness or to the effects of homelessness on children (Aptekar, 1994).

Keeping in view the dearth of studies on the quality of life of rag pickers especially associated with the depression and pessimism which may lead to the development of a sense of hopelessness among the vulnerable adolescents. The study was designed to examine the quality of life and hopelessness among the homeless rag pickers besides that the possible linkage between the two variables namely quality of life and hopelessness were also examined in the study The following hypotheses were formulated in the light of available literature:

1. There would be difference in the quality of life of rag pickers and non- pickers.

2. There would be difference in the feeling of hopelessness among rag pickers and non- rag pickers.

3. Quality of life scores would be correlated with the scores of hopelessness among the rag pickers and non-rag pickers.

\section{Method}

\section{Sample}

The study was conducted on male rag pickers as most of the rag pickers are found to be male and easily accessible. The sample consisted of hundred and twenty (120) male adolescent participants ranging from age $12-18$ years. Out of 120 , sixty (60) participants were rag pickers who were engaged in rag picking works only and living in night shelters (Rainbasera). The remaining sixty (60) were nonrag pickers living in slums. Out of sixty in each group fifty four were belonging to the age group of 12-16. The rag pickers were randomly taken from their shelter homes as rag pickers from every third shelter home were personally contacted by the investigators. The purpose of study and nature of questions to be asked were explained to each participant in individual setting to take their verbal consent. After obtaining the consent both the tools were administered on each of them. Sixty non- rag picker participants were also selected randomly from different slums of nearby locality. Every third slum was identified first and adolescents of similar age but dependent on their parents were contacted individually. They were also explained about the study for obtaining their consent. The two tools were administered on each of them in individual setting. The non- rag pickers were attending municipal or community schools and their parents were engaged in works like rickshaw pulling, dish washing, labour, catering, housekeeping etc. Only male non-rag-pickers were taken into consideration to control the gender variability.

\section{Measures}

World Health Organization (1998) Quality Of Life-BREF (Shorter Version) questionnaire was used to assess quality of life of the participants. The scale consists of 26 items with five point Likert type scale. The items framed on four domains: Physical Health items include "To what extent do you feel that physical pain prevents you from doing what you need to do?", Psychological Health includes "How well are you able to concentrate?", Social Relationships includes like "How satisfied are with the support you get from your friends?" whereas the Environment related "How safe do you feel in your daily life? The scale has good discriminant 
validity, content validity and test-retest reliability. Domains score produced by the questionnaire have been shown to correlate at around 0.9 with The World Health Organisation Quality of Life-100 domain scores. The four domain scores are scaled in a positive direction with higher scores indicating a higher quality of life.

The Beck Hopelessness Scale developed by Beck and Steer (1993) was used to assess the feeling of hopelessness. It is a self-report measure of one's negative expectations regarding the future. It consists of 20 true-false items and the items include "I look forward to the future with hope and enthusiasm" and "My future seems dark to me". The Beck Hopelessness Scale moderately correlates with the Beck Depression Inventory. The internal reliability coefficients are reasonably high (Pearson $\mathrm{r}=.82$ to .93 ).

\section{Procedure}

The rag pickers and the non-rag pickers were individually contacted by the investigators at their respective locations.
At first each of them were explained the purpose of the study and their verbal consent was sought individually before administration of the tools. The questions of the two tools were asked by the participants on by one.

\section{Results}

Table 1 showing mean for the overall as well as the dimension wise scores of quality of life. The overall mean scores were 50.16 with SD of 11.55 and 67.16 with SD of 19.03 for the rag pickers and the non-rag picker adolescents respectively. The differences in the mean of the two groups was so large that it was also found statistically significant as ' $t$ ' $=4.18$. The effect size of overall scores of quality of life was found .47 as "medium" that showed that a non-overlap of $27.4 \%$ in the two distributions. The results indicating poor quality of life of the rag pickers as compare to the non-rag pickers. Hence the hypothesis was found confirmed.

Table 1. Mean, S.D of quality of life scores of adolescents of the two groups and ' $t$ ' values for the reliability of the differences between the two means.

\begin{tabular}{|c|c|c|c|c|c|c|c|c|c|}
\hline & Group & $N$ & Mean & $S . D$ & $t$-value & $d f$ & $p$ & Cohen's d & ES \\
\hline \multirow[t]{2}{*}{ Physical Health } & Rag pickers & 60 & 14.76 & 3.9 & \multirow[t]{2}{*}{3.42} & \multirow[t]{2}{*}{118} & \multirow[t]{2}{*}{0.103} & \multirow[t]{2}{*}{-0.88} & \multirow[t]{2}{*}{-0.4} \\
\hline & Non-rag pickers & 60 & 18.73 & 5.01 & & & & & \\
\hline \multirow[t]{2}{*}{ Psychological Health } & Rag pickers & 60 & 13 & 3.93 & \multirow[t]{2}{*}{3.82} & \multirow[t]{2}{*}{118} & \multirow[t]{2}{*}{0.055} & \multirow[t]{2}{*}{-0.098} & \multirow[t]{2}{*}{-0.44} \\
\hline & Non-rag pickers & 60 & 17.7 & 5.46 & & & & & \\
\hline \multirow{2}{*}{ Social-Relationship } & Rag pickers & 60 & 6.93 & 2.15 & \multirow{2}{*}{2.92} & \multirow{2}{*}{118} & \multirow{2}{*}{0.143} & \multirow{2}{*}{-0.75} & \multirow{2}{*}{-0.35} \\
\hline & Non-rag pickers & 60 & 8.8 & 2.77 & & & & & \\
\hline \multirow[t]{2}{*}{ Environment Related } & Rag pickers & 60 & 15.46 & 4.15 & \multirow[t]{2}{*}{4.25} & \multirow[t]{2}{*}{118} & \multirow[t]{2}{*}{0.003} & \multirow[t]{2}{*}{-1.1} & \multirow[t]{2}{*}{-0.48} \\
\hline & Non-rag pickers & 60 & 21.93 & 7.21 & & & & & \\
\hline \multirow{2}{*}{$\begin{array}{c}\text { Quality of Life Overall } \\
\text { scores }\end{array}$} & Rag pickers & 60 & 50.16 & 11.55 & \multirow[t]{2}{*}{4.18} & \multirow[t]{2}{*}{118} & \multirow[t]{2}{*}{0.001} & \multirow[t]{2}{*}{-1.07} & \multirow[t]{2}{*}{-0.47} \\
\hline & Non-rag pickers & 60 & 67.16 & 19.03 & & & & & \\
\hline
\end{tabular}

Table 2. Mean, S.D of hopelessness scores of adolescents of the two groups and ' $t$ ' for the reliability of the difference between the two means.

\begin{tabular}{|c|c|c|c|c|c|c|c|c|c|}
\hline variable & Group & $N$ & Mean & S.D & $t$-value & $d f$ & $P$ & Cohen's $d$ & ES \\
\hline \multirow[t]{2}{*}{ Hopelessness } & Rag pickers & 60 & 14.4 & 3.01 & \multirow[t]{2}{*}{4.49} & \multirow[t]{2}{*}{118} & \multirow[t]{2}{*}{0.047} & \multirow[t]{2}{*}{1.16} & \multirow[t]{2}{*}{0.5} \\
\hline & Non-rag pickers & 60 & 9.96 & 4.49 & & & & & \\
\hline
\end{tabular}

Table 3. Correlation coefficient between quality of life and hopelessness scores $(n=120)$.

\begin{tabular}{|c|c|c|c|c|c|}
\hline Variables & Physical Health & Psychological & $\begin{array}{c}\text { Social-Relationshi } \\
\mathrm{p}\end{array}$ & Environment & Quality of Life \\
\hline Hopelessness & -.66 & -.61 & -.59 & -.64 & -.69 \\
\hline
\end{tabular}

Table 4. Correlation coefficient between quality of life and hopelessness scores for the two groups of adolescents namely rag pickers and non-rag pickers.

\begin{tabular}{|c|c|c|c|c|c|c|}
\hline Groups & & $\begin{array}{c}\text { Physical } \\
\text { Health }\end{array}$ & Psychological & $\begin{array}{c}\text { Social } \\
\text { Relationship }\end{array}$ & Environment & Quality of Life \\
\hline Non-Rag pickers & Hopelessness & -.14 & $-.24^{*}$ & -.11 & .09 & -.12 \\
\hline Rag Pickers & Hopelessness & $-.81^{* *}$ & $-.62^{* *}$ & $-.72 * *$ & $-.76^{* *}$ & $-.78^{* *}$ \\
\hline
\end{tabular}


Table 2 showing mean scores of hopelessness among the two groups of adolescents which were found to be 14.40 with SD of 3.0 for the rag pickers and 9.96 with SD of 4.49 for the non-rag pickers. The difference was quite substantial and significant as the $t$ value was found 4.49. The effect size was found .50 as "medium" that indicated that a non-overlap of $33 \%$ in the two distributions. Thus rag pickers were suffering from deeper sense of hopelessness than their non-rag picker counterpart. Hence the hypothesis was found confined.

The results presented in table 3 showed that the overall relationship between the two variables was negative but significant as $\mathrm{r}=-.69$, which was statistically significant beyond the 0.01 level of confidence. Meaning there by better will the quality of life lower will be feeling of hopelessness. In other words quality of life and hopelessness go opposite to each other. As the $r$ found -.69 the coefficient of determination $\left(r^{2}\right)$ is 0.477 , meaning that $47.7 \%$ of the variance of either is shared with other variables. Hence, the hypothesis was found confirmed.

The results presented in table 4 showed that the relationship between the two variables was negative but significant among two different groups namely rag pickers and non-rag pickers as $\mathrm{r}=-.78$ and -.12 respectively, which was statistically significant beyond the 0.01 level of confidence for the group of rag pickers. Meaning there by higher will the quality of life lower will be sense of hopelessness among the group of rag pickers. In other words the intensity of the relationship was strong among the group of rag pickers between said two variables namely quality of life and hopelessness as compare to their counterpart.

\section{Discussion}

Since the rag pickers constituted a homogeneous group in terms of age, gender, livelihood etc. as the participants in the present study were between 12-18 years of age and all of them were male. The idea behind the study on male was that male rag pickers are found in majority and can be easily contacted. The study of Singh, Sareen, Ojha and Saren (2008), also confirmed that majority of the street children were males $(71 \%)$ because parents usually insists the male offspring should work as a labour at places far away from the home.

The results indicated that quality of life of the non- rag picker adolescents who were living in slums and were dependent on the parents were much better in terms of the physical health and psychological health. Since they were enjoying parental support and maintaining good social relationship via community participation their quality of life was much better than the rag pickers despite of the poverty. As far as rag-pickers were concerned their quality of life was significantly poor than the non- rag pickers. Rag pickers were found to be vulnerable to physiological health and psychological wellbeing. Mamata (2004) reported the working conditions of child garbage and rag-pickers increase the risk of disease and disability through exposure to lead and mercury, buckling of the back because they have to lift heavy sacks of rags, and the presence of parasites. Ashoka (2006) explained that street children are involved in activities which are harmful to their physical and mental health.

The continuous involvement in rag picking from the community garbage and waste products sometimes cause serious physical diseases \& illnesses. Kamat (1999) revealed that child Rag pickers are subjected to chemical poisons and infections because of malnutrition they suffer from retarded growth and anemia. Rag pickers are usually susceptible to diseases like tuberculosis and cancer due to their exposure to hazardous materials and addicted to chewing and smoking tobacco.

Rag-pickers survive on streets without having permanent shelter through unprotected and uncertain hard labour on the streets for the livelihood. The difficulties in survival on the streets were highlighted by the large number of homeless youth who regularly lack shelter and go hungry (Antoniades \& Tarasuk, 1998). Moreover, street life presents numerous dangers and stresses in the form of physical and sexual assaults and other types of victimization (Whitbeck Hyot and Bao, 2000).

Life on streets or being homeless makes them vulnerable to psychological problems as well. Due to poor psychological well-being and to cope daily hassles they smokes 'cigarettes and Beedi', alcohol, drugs and practice prostitution and homosexuality. Such malpractices result in psychological trauma and chances of STD, HIV/AIDS. Often child rag-pickers also involves in robbery and gambling. Street children and adolescents face many dangers and sources of stress in their lives. To earn bread and butter, they engage in activities such as trying to find work panhandling, survival sex (sex for food, shelter etc.), drugdealing, and theft (Hagan \& McCarthy, 1997; Kipke Montgometry, Simon and Iverson, 1997).

The poor quality of life sometimes reflected in poor mental health and depression which result in pessimism and hopelessness. Hopelessness is characterized by persistently negative feelings and expectations about the future as well as loss of motivation. A sense of hopelessness seems to lead to increasingly negative evaluations of new situations and less effective coping strategies; thus, the perception is that one will not accomplish anything meaningful (Avci, Okanli, Karabulutlu, and Bilgili, 2009). As the results revealed hopelessness among the street children was higher as compare to children who had parental support and proper roof on them. Children living with parents and attending municipal or other school had different life style. Parental supports were helpful in developing positive hope towards future. But in the case of street children they are more prone to physiological and psychosocial challenges. Gledenhuys' (2001) suggested that street youth may also experiences of hopelessness, inferiority, despondency, rebellion, feeling of uncertainty about life in general and rage, they developed a feeling of rejection and desertion as results of circumstances.

As far as relationship between the quality of life and 
hopelessness was concerned it was found negative. The negative relationship was very much obvious because the good quality of life indicates better future or hope otherwise feeling of hopelessness, distress, anxiety, depression, isolation etc. are developed. Poor the quality of life higher will be the feeling of hopelessness and vice versa. Cotton, Levine, Fitzpatrick, Dold, and Taro (1999) also reported positive correlation between spiritual well-being and quality of life, a significant positive correlation between spiritual well-being and fighting spirit, and a significant negative correlation between quality of life and the use of a helpless/hopeless adjustment style.

To draw coping strategies or mechanism for the rag-pickers is a major challenge in adverse and rummage life. Kombarakaran (2004) reported street children face several challenges in their search of food, shelter, employment, safety and medical care. They commonly depend on the peers, non-governmental agencies and their own resourcefulness to survive on the streets. While the majority uses positive mechanism to cope with their daily stresses, some children also employ maladaptive strategies such as using alcohol, drugs, visiting prostitutes etc. The study also reveals that these "children of the street" are not entirely on their own but depends on various connections with substitute's family members and or their peers to cope with life. The stress and coping strategies of the children of the street are similar to those of others street children who live with their families and work on streets. Hai (2014) reported that in response to physical, economic and emotional insecurity and lack of protection the respondents used to make friendship with other street children, try to cope with the emotional vacuum within the surrounding environment.

In the present scenario rag-pickers are the marginalized and special backward section of the society. They are not educationally, economically and socially sound and depend on collecting and selling waste for re-cycling process for their livelihood. They are totally depends on peers and non-government organization for the assistance. For the benefit of the particular section's people should be sensitize and aware of child rights through large scale campaign, free and compulsory education for all, rehabilitation \& reintegration programme should be launched and income generating programmes would be helpful.

\section{Conclusions}

The present study examines the extent of quality of life and hopelessness among rag-pickers and relationship between both the variables. The 'rag pickers', who work on the streets and spends nights in shelter homes were suffering from problem of poor quality of life and sense of hopelessness. Quality of life of adolescent rag pickers significantly poor and lead to more vulnerability in terms of deprived physiological health and psychosocial wellbeing as results they tends to develop negative cognitive schemas about future. Need to mobilize the community about child rights and change pre-dispositional idea/thoughts regarding rag-pickers, income generating programmes should be introduce and make compulsory education for all. As finding reveals that rag-pickers had poor quality of life and high sense of hopelessness not a good indicator for the survival of marginalized section of rag-pickers. This research paper is limited to two variables and male participants to control the gender variability. To establish sound generalization other variables like substance abuse, mental health and other psycho-social concern should be considered and sample size should be large and includes both male and female adolescents.

\section{REFERENCES}

[1] Abdul Kalam A.P.J.- Former President of India(19 Sep, 2008)"Child Rag pickers are not Street-Children". www.thehindu.com/holnus

[2] Antoniades, M., \& Tarasuk, V. (1998). A survey of food problems experienced by Toronto street youth. Canadian Journal of Public Health, 89(6), 371-375.

[3] Aptekar, L. (1994). Street Children in developing World: A review of their condition, Cross Cultural Research. The Journal of Comparative Social Science, 28, 195-224.

[4] Ashoka. (2006). Child and Law, Sudha Publication, Mysore

[5] Avci, I,A., Okanli, A., Karabulutlu, E. \& Bilgili, N. (2009). Women's marital adjustment and hopelessness levels after mastectomy. European Journal of Oncology Nursing, 13, 299- 303.

[6] Beck, A. \& Steer, R. (1993). Beck Hopelessness Scale Manual. San Antonio, TX: The Psychological Corporation.

[7] Cotton, S. P., Levine, E. G., Fitzpatrick, C. M., Dold, K. H., \& Taro, E. (1999). Exploring the relationships among spiritual well-being, quality of life, and psychological adjustment in women with breast cancer. Psycho-oncology, 8, 429-438.

[8] DiBiase, R. and Waddell, S. (1995). Some effects of homelessness on the psychological functioning of pre-schoolers. Journal of Abnormal Child Psychology,23, 783- 792.

[9] Edelman, M. W., \& Mihaly, L. (1989). Homeless families and the housing crisis in the United States. Children and Youth Services Review, 11, 99-108.

[10] Geldenhuys, J, L. (2001). The South African black adolescent street children as problematic education situation. International Journal of Adolescence and Youth, 9(2-3), 227-243.

[11] Hagan, J., \& McCarthy, B. (1997). Mean streets: Youth crime and homelessness. Cam - bridge: Cambridge University Press.

[12] Hai, A. (2014). Problem faced by the street children: A study on some selected places in Dhakha city, Bangladesh, International Journal of Scientific \& Technology Research, 3 (10), 45-56. 
[13] Kamat. K.L. (1999). Rag-pickers of India. Retrieved from www.Ragpickers.htm.

[14] Kipke, M. D., Montgomery, S., Simon, T. R., \& Iverson, E. F. (1997). Substance abuse disorders among runaway and homeless youth. Substance Use and Misuse, 32, 969-986.

[15] Kombarakaran, F.A. (2004). Street Children of Bombay: Their Stresses and Strategies of Coping, Children and Youth Services Review, 26, 853-871.

[16] Marshall, G.N., M.A. Burnam, P. Koegel, G. Sullivan and B. Benjamin (1996). Objective life circumstances and life satisfaction: Results from the Course of Homelessness Study. Journal of health \& Behavior, 37, 44-58.

[17] McLaughlin, J., Miller, P., \& Warwick, H. (1996). Deliberate self-harm in adolescents: Hopelessness, depression, problems and problem-solving. Journal of Adolescence, 19, 523-532.

[18] Metalsky, G.I., \& Joiner, Jr., T. E. (1992) .Vulnerability to depressive symptomatology: A prospective test of the diathesis stress and causal mediation components of the hopelessness theory of depression. Journal of Personality and Social Psychology, 63, 667-675.

[19] Rajawat, M. (2004). Child Labour - The Indian Perspective, Kilaso Books, New Delhi.

[20] Singh D., Sareen N., Ojha A., and Sareen D. (2008): Street Children of Udaipur: Demographic Profile and Future Prospects. Studies Tribes and Tribals, 6(2): 135-139.

[21] Whitbeck, L.B., Hoyt, D. R., \& Bao, W. (2000). Depressive symptoms and co-occurring depressive symptoms, substance abuse, and conduct problems among run away and homeless adolescents. Child Development, 71(3), 721-732.

[22] WHOQOL Group (1998). Development of the World Health Organization WHOQOL-BREF quality of life assessment. Psychological Medicine; 28 (3): 551-558. 